\title{
Activities of Daily Living and Life-Space Mobility in Older Adults with Chronic Obstructive Pulmonary
}

\section{Disease}

This article was published in the following Dove Press journal:

International Journal of Chronic Obstructive Pulmonary Disease

\author{
Isabel Fialho Fontenele \\ Garcia (ID) \\ Carina Tiemi Tiuganji \\ Maria do Socorro Morais Pereira \\ Simões (iD ${ }^{2}$ \\ Adriana Claudia Lunardi (iD) 1,3 \\ 'Master's and Doctoral, Programs in \\ Physical Therapy, Universidade Cidade de \\ São Paulo, São Paulo, SP, Brazil; \\ ${ }^{2}$ Department of Human Movement \\ Sciences, Universidade Federal de São \\ Paulo, Santos, SP, Brazil; ${ }^{3}$ Department of \\ Physical Therapy, School of Medicine, \\ Universidade de São Paulo, São Paulo, SP, \\ Brazil
}

Purpose: The aim of this study was to investigate whether limitation during the performance of activities of daily living (ADL) was associated with life-space mobility in older people with chronic obstructive pulmonary disease (COPD), and to generate a regression model for life-space mobility score.

Patients and Methods: This cross-sectional study with a convenience sample included older people (aged $\geq 60$ years old) with COPD. We assessed participants' lung function (spirometry), life-space mobility (University of Alabama at Birmingham Study of Aging Life-Space Assessment questionnaire), severity of dyspnea (Modified Dyspnea Index) and limitation during the performance of ADL (London Chest Activity of Daily Living). We used Pearson's correlation to investigate the associations between the measures, and multiple linear regression to detect which of the measures influenced life-space mobility. Statistical significance was set at $5 \%$.

Results: Fifty participants completed all the assessments (29 females [58\%]; mean \pm SD age of $67 \pm 6$ years old, $\mathrm{FEV}_{1} 47 \pm 29 \%$ of predicted, and body mass index $22.5 \pm 11.6 \mathrm{~kg} / \mathrm{m}^{2}$ ). Their mean scores for life-space mobility and for limitation during the performance of ADL were $49.7 \pm 27.2$ and $16.46 \pm 9.74$, respectively. We found a strong inverse correlation between limitation during the performance of ADL and life-space mobility $(r=-0.57$, $\mathrm{p}=<0.01)$ as well as between severity of dyspnea and life-space mobility ( $\mathrm{r}=0.86$, $\mathrm{p}=<0.01$ ). Both sex and limitation during the performance of ADL were considered as independent factors associated to life-space mobility $\left(\mathrm{R}^{2}=0.56\right)$.

Conclusion: In this study, limitations during the performance of ADL and dyspnea had a strong correlation with life-space mobility in older adults with COPD. Also, alongside sex, the limitation during the performance of ADL is an independent factor associated with lifespace mobility in a regression model.

Keywords: COPD, older adult, mobility limitation, activities of daily living

\section{Introduction}

Chronic obstructive pulmonary disease (COPD) leads to progressive worsening of dyspnea and fatigue, a more inactive lifestyle as well as physical deconditioning, which is aggravated by normal aging. ${ }^{1}$ Peripheral muscle dysfunction caused by COPD may have an important impact on functional capacity, making older people with COPD both more prone to disability and less independent when performing activities of daily living. ${ }^{2}$ Therefore, instruments that adequately assess limitations during the performance of activities of daily living can provide information on the effectiveness of the
Lunardi

Master's and Doctoral Programs in Physical Therapy, Universidade Cidade de São Paulo, 448/475 Cesário Galeno Street, São Paulo 0307I-000, SP, Brazil

Tel +55 II $2178-1310$

Fax +55 II $2178-1355$

Email adriana.lunardi@unicid.edu.br 
therapeutic strategies offered to people with COPD undergoing pulmonary rehabilitation programs. ${ }^{3}$

Limitation during the performance of activities of daily living in people with COPD can be assessed using the London Chest Activity of Daily Living scale. ${ }^{2}$ However, an accurate measure of the individual's physical function requires more than the assessment of their performance during activities of daily living. This is because physical function also encompasses the individual's participation in social activities. ${ }^{4}$ The University of Alabama at Birmingham Study of Aging Life-Space Assessment questionnaire provides a measure of participation in social activities. ${ }^{5}$ Limitations on life-space mobility assessed by this questionnaire reflected more the individuals' lifestyle than the physical ability. ${ }^{5}$ Life-space mobility is scored considering how far, how independent, and how frequent an older adult is able to move. ${ }^{6}$ The score considers the places the person went (bedroom/other room of the house, outside area of the house, neighborhood, other neighborhoods, and other cities), how frequent they moved among these places (less than once a week, 1 to 3 times per week, 4 to 6 times per week, daily), and how independent they moved (personal assistance needed, equipment needed, or no personal assistance or equipment). ${ }^{6}$ Life-space mobility has been used to assess mobility of community-dwelling older people with different disease profile, disability levels, as well as different environmental and social resources. In addition, this measure may show the individual's inability to participate in social activities, as engagement in social activities demands people to move through life-spaces. ${ }^{5}$ Hence, life-space mobility can be influenced by environmental, cognitive and physical factors. ${ }^{7}$ Being female and older is associated with greater limitations on life-space mobility. In addition, women and older adults have greater limitations on their autonomy. ${ }^{8}$ Of note, in older people, impairment in life-space mobility seems to lead to worse quality of life, ${ }^{7}$ social isolation, ${ }^{9}$ symptoms of depression ${ }^{10}$ and may lead to physical inactivity.

Therefore, in order to develop interventions aimed at improving functional independence and participation in social activities of older people with COPD, it is important to investigate the association between the systemic effects of COPD and life-space mobility. The University of Alabama at Birmingham Study of Aging Life-Space Assessment questionnaire has already been used in older people with COPD ${ }^{11}$ and a relationship between the systemic effects of COPD (such as dyspnea and peripheral muscle strength) and life-space mobility was found. ${ }^{11}$ However, there is a lack of information on the relationship between the performance during activities of daily living and life-space mobility in this population. Hence, the aim of the current study was to investigate whether limitation during the performance of activities of daily living was associated with life-space mobility in older people with COPD, and to generate a regression model for life-space mobility score.

\section{Materials and Methods}

\section{Participants}

This cross-sectional study was approved by the Research Ethics Committee from both the UNICID (CAAE: 29380314.0.0000.0064) and the Mandaqui's Hospital Group (CAAE: 29380314.0.3001.5551), where participant recruitment and data collection were undertaken from January to May 2017. This study had no sample size calculation because it was conducted secondarily to the one previously published, ${ }^{11}$ therefore we used a convenience sample. This study was conducted in accordance with the Declaration of Helsinki. Written informed consent was obtained from all participants.

Of the 70 older people with COPD from the Respiratory Medicine service of the Mandaqui's Hospital Group who were deemed eligible for inclusion, 50 (71\%) took part in the study. The other 20 older people with COPD who were eligible declined to participate in the study. The inclusion criteria were: older adults aged $\geq 60$ years old, under the care and management of physicians from the outpatient Respiratory Medicine clinic of the Mandaqui's Hospital Group for at least 6 months, and with a post-bronchodilator $\mathrm{FEV}_{1} / \mathrm{FVC}<70 \%$ predicted. ${ }^{1}$ Exclusion criteria comprised: presence of musculoskeletal or cognitive limitations that could compromise participant safety during the assessments or completion of the assessments, participation in pulmonary rehabilitation program or regular physical activity in the past 6 months, and presence of a physician-diagnosed respiratory symptom related to heart disease or non-respiratory causes.

\section{Procedures}

Each potential participant was invited to take part in the study and, following written, informed consent, they underwent the assessments that determined whether they met the eligibility criteria for the study. Subsequently, eligible participants were instructed on the study procedures and 
measures were collected of medical history and anthropometric data, lung function, severity of dyspnea, life-space mobility, and limitation during the performance of activities of daily living.

\section{Measurements}

\section{Medical History and Anthropometric Data}

The study data collection sheet included data on: personal details, anthropometric measures (height and body-weight measured according to the recommendations of the National Institute of Health, Heart, Lung and Blood), ${ }^{12}$ comorbidities, smoking history (non-smoker, current or ex-smoker), smoking load in pack years (number of cigarette packs/day multiplied by the number of years of cigarette smoking), alcohol consumption, presence of respiratory symptoms (cough, expectoration, wheeze or dyspnea), and disease severity according to the GOLD criteria (GOLD 1 - Mild: $\mathrm{FEV}_{1} \geq 80 \%$ of the predicted; GOLD 2 - Moderate: $50 \% \leq \mathrm{FEV}_{1}<80 \%$ of the predicted; GOLD 3 - Severe: $30 \% \leq \mathrm{FEV}_{1}<50 \%$ of the predicted; GOLD 4 - Very severe: $\mathrm{FEV}_{1}<30 \%$ of the predicted). ${ }^{1}$

\section{Lung Function}

Lung function was measured via spirometry (Spirobank II - Medical International Research, EUA), following the technical procedures and the acceptability and reliability criteria from the American Thoracic Society and European Respiratory Society. ${ }^{13}$ We registered the forced expiratory volume in the first second $\left(\mathrm{FEV}_{1}\right)$, forced vital capacity (FVC), and forced expiratory flow from $25 \%$ to $75 \%$ of the vital capacity $\left(\mathrm{FEF}_{25-75 \%}\right)$. Results were expressed in absolute values and as percentage of the predicted value for a healthy Brazilian population. ${ }^{14}$

\section{Life-Space Mobility}

To assess life-space mobility we used the Brazilian version of the University of Alabama at Birmingham Study of Aging Life-Space Assessment questionnaire. ${ }^{15-17}$ The questionnaire includes questions pertaining to five levels of spaces that the individual visited in the 4 weeks prior to the assessment. The items of the questionnaire include: life-space level (room where the person sleeps, other room in their home, areas outside their home, neighborhood, other neighborhoods within their city, and other cities), frequency (less than once a week, one to three times per week, four to six times per week or everyday) and level of independence (personal assistance, equipment only, no equipment or personal assistance). ${ }^{15,18}$ The final score ranges from 0 to 120 , and it combines the scores for each life-space level. Higher scores indicate greater lifespace mobility. ${ }^{15}$

\section{Severity of Dyspnea}

We used the Brazilian version of the Modified Dyspnea Index (MDI) to assess the severity of dyspnea. ${ }^{19}$ The MDI comprises three domains: functional impairment, magnitude of task and magnitude of effort. Two separate scores are used to inform functional impairment: one to measure functional impairment at home, and the other one to measure functional impairment in the workplace. These two scores are combined to derive a composite score for functional impairment, which ranges from 0 to 4 . The scores for the domain's magnitude of task and magnitude of effort also range from 0 to 4 and, therefore, the total score of the MDI ranges from 0 to 12 . Lower scores indicate more severe dyspnea. ${ }^{19}$

\section{Limitation During the Performance of Activities of Daily Living}

To this measure, we used the Brazilian version of the London Chest Activity of Daily Living scale, which has been demonstrated to be valid and reliable. ${ }^{2,20}$ The London Chest Activity of Daily Living scale comprises 15 items grouped in five domains: self-care (four items), domestic activities (six items), physical activity (two items), and leisure activities (three items). Each item is scored from 0 to 5. The responses are as follows: $0-$ would not do it anyway; 1 - I do not get breathless; 2 - I get moderately breathless; 3 - I get very breathless; 4 - I cannot do this anymore, and; 5 - someone else does it for me. Each domain is scored separately, and a total score is calculated by summing the scores of the four domains. Higher scores indicate greater limitation during the performance of activities of daily living. ${ }^{2}$

\section{Statistical Analysis}

We used descriptive statistics to report on clinical characteristics, severity of dyspnea, life-space mobility and limitation during the performance of activities of daily living. We conducted Pearson's correlation to investigate the associations between age, BMI, $\mathrm{FEV}_{1}$, severity of dyspnea and limitation during the performance of activities of daily living with life-space mobility. Weak, moderate and strong correlations were set at $r=0.10$ to $0.29, r=0.30$ to 0.49 , and $r=0.50$ to 1 , respectively. ${ }^{21}$ Further, we tested the following variables in the bivariate model: sex, body-mass index (BMI), smoking 
history, $\mathrm{FEV}_{1}$, severity of dyspnea, and limitation during the performance of activities of daily living had on life-space mobility. The aim was to build a multiple linear regression using the variables which presented statistically significant association with life-space mobility score. Then, the final regression model included the sex and limitation during the performance of activities of daily living as independent variables, because these two were the only that demonstrated to be independently associated with life-space mobility (dependent variable). Statistical significance was set at $5 \%$.

\section{Results}

\section{Characteristics of Participants}

Fifty participants aging 60 to 82 years old were included and completed all the assessments. The characteristics of participants including age, sex, anthropometric data, number of retirees, medical history, severity of dyspnea as well as the University of Alabama at Birmingham Study of Aging Life-Space Assessment score (ranging from 22 to 90 points) and the London Chest Activity of Daily Living score are presented in Table 1. Figure 1 shows the distribution of the scores on the University of Alabama at Birmingham Study of Aging Life-Space Assessment questionnaire.

\section{Correlation Between Age, BMI, FEV , Severity of Dyspnea, Limitation of Activities of Daily Living and Life-Space Mobility}

We found a strong inverse correlation between limitation during the performance of activities of daily living (London Chest Activity of Daily Living score) and lifespace mobility, with power of $90 \%$ for alpha $=0.05$. Further, except for the domain "domestic activities", that demonstrated a moderate inverse correlation, the three other domains of the London Chest Activity of Daily Living scale presented a strong inverse correlation with life-space mobility (Table 2; Figure 2).

\section{Regression Model of Life-Space Mobility}

Sex and limitation during the performance of activities of daily living (assessed via the London Chest Activity of Daily Living scale) were considered factors that were independently associated with life-space mobility and were included in the regression model (Table 3). Dyspnea did not remain in the regression model, even though it strongly correlated with
Table I Participant Characteristics $(n=50)$

\begin{tabular}{|c|c|}
\hline Variables & Values \\
\hline Age, years & $67 \pm 6$ \\
\hline Female, $\mathrm{n}(\%)$ & $29(58 \%)$ \\
\hline Body weight, kg & $59 \pm 31$ \\
\hline BMI, $\mathrm{kg} / \mathrm{m}^{2}$ & $22.5 \pm 11.6$ \\
\hline Retirees, n (\%) & $19(38 \%)$ \\
\hline Comorbidities, n (\%) & $30(60 \%)$ \\
\hline $\mathrm{SAH}, \mathrm{n}(\%)$ & $26(52 \%)$ \\
\hline CHF, n (\%) & $6(12 \%)$ \\
\hline Diabetes, n (\%) & II (22\%) \\
\hline Current smoker, n (\%) & $33(66 \%)$ \\
\hline Alcohol consumption, n (\%) & $6(12 \%)$ \\
\hline \multicolumn{2}{|l|}{ Self-Reported Symptoms } \\
\hline Cough, n (\%) & $18(36 \%)$ \\
\hline Expectoration, n (\%) & $15(30 \%)$ \\
\hline Wheeze, n (\%) & $24(48 \%)$ \\
\hline Dyspnea, n (\%) & $43(86 \%)$ \\
\hline GOLD I, n (\%) & $4(8 \%)$ \\
\hline GOLD 2, n (\%) & $27(54 \%)$ \\
\hline GOLD 3, n (\%) & 17 (34\%) \\
\hline GOLD 4, n (\%) & $2(4 \%)$ \\
\hline $\mathrm{FEV}_{1}, \%$ predicted & $47 \pm 29$ \\
\hline FVC, \% predicted & $51 \pm 29$ \\
\hline $\mathrm{FEF}_{25-75 \%}, \%$ predicted & $39 \pm 31$ \\
\hline Severity of dyspnea (MDI), units & $6.26 \pm 3.43$ \\
\hline Life-space mobility, units & $49.74 \pm 27.21$ \\
\hline Restricted life-space mobility, n (\%) & $25(50 \%)$ \\
\hline Limitation during $A D L$, units & $16.46 \pm 9.74$ \\
\hline Self-care, units & $4.7 \pm 2.9$ \\
\hline Domestic activities, units & $5.1 \pm 4.5$ \\
\hline Physical activity, units & $3.3 \pm 1.9$ \\
\hline Leisure, units & $3.3 \pm 2.0$ \\
\hline
\end{tabular}

Notes: Data are presented as mean \pm standard deviation or absolute number (\%); $\mathrm{FEV}_{1}$, FVC, and $\mathrm{FEF}_{25-75 \%}$ are presented as \% predicted. ${ }^{14}$ Restricted Life-Space mobility $=$ the University of Alabama at Birmingham Study of Aging Life-Space Assessment score $\leq 60 .{ }^{18}$ Abbreviations: $\mathrm{n}$, absolute number; \%, percentage; $\mathrm{kg}$, kilogram; $\mathrm{km} / \mathrm{m}$, ${ }^{2}$ kilogram/ square meter; BMI, body mass index; SAH, systemic arterial hypertension; CHF, congestive heart failure; GOLD, Global Initiative for Chronic Obstructive Lung Disease; $\mathrm{FEV}_{\mathrm{l}}$, forced expiratory volume in one second; $\mathrm{FVC}$, forced vital capacity; $\mathrm{FEF}_{25-75 \%}$, forced expiratory flow from $25 \%$ to $75 \%$ of vital capacity; MDI, Modified Dyspnea Index; $A D L$, activities of daily living. 


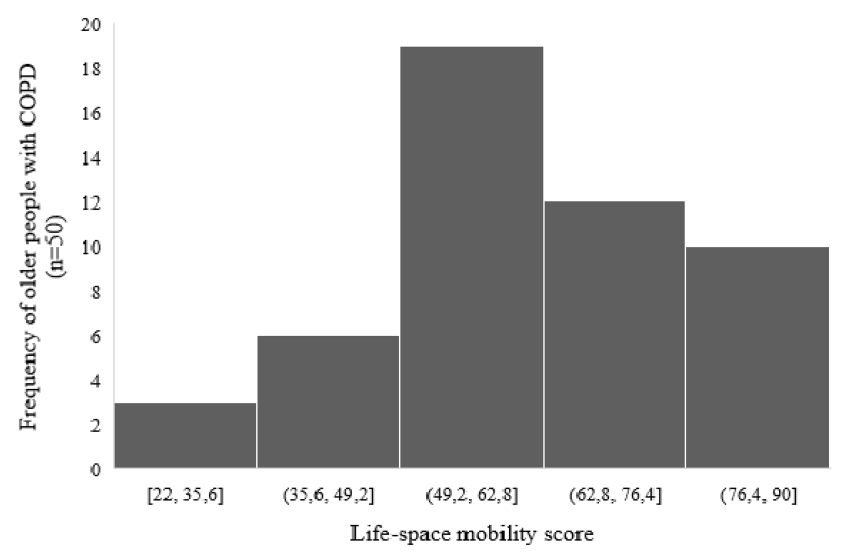

Figure I Distribution of life-space mobility scores among older adults with COPD. Abbreviation: COPD, chronic obstructive pulmonary disease.

life-space mobility in the bivariate model. Hence, limitation during the performance of activities of daily living and sex were likely to provide an estimate of life-space mobility score (measured via the University of Alabama at Birmingham Study of Aging Life-Space Assessment), with an $\mathrm{R}^{2}=0.56$. The equation is as follows:

Life-space mobility $=70.961+\left(11,215 * \operatorname{sex}^{1}\right)$ $-(0.747 * \text { London Chest Activity of Daily Living score })^{1}$

$$
\text { Sex : } 0 \text { (female), 1(male) }
$$

\section{Discussion}

Our results demonstrate that the limitation during the performance of activities of daily living is associated with life-space mobility in older people with COPD. The novel finding of the current study is the strong association between a variable that represents a systemic effect of

Table 2 Correlations Between Life-Space Mobility, Age, BMI, FEV, Severity of Dyspnea and Limitation During the Performance of Activities of Daily Living in Older People with COPD

\begin{tabular}{|l|l|l|}
\hline Variables & $\mathbf{r}$ & p-value \\
\hline Age & -0.01 & 0.03 \\
BMI & -0.19 & 0.18 \\
FEV & 0.20 & 0.15 \\
Severity of dyspnea (MDI) & 0.86 & $<0.01$ \\
London scale total score & -0.57 & $<0.01$ \\
Self-care & -0.58 & $<0.01$ \\
Domestic activities & -0.33 & 0.01 \\
Physical activity & -0.63 & $<0.01$ \\
Leisure activities & -0.56 & $<0.01$ \\
\hline
\end{tabular}

Notes: r, Pearson's correlation; p-value, statistical significance of the Pearson's correlation.

Abbreviations: BMI, body mass index; $\mathrm{FEV}_{1}$, forced expiratory volume in I s; MDI, Modified Dyspnea Index; London scale, London Chest Activity of Daily Living.
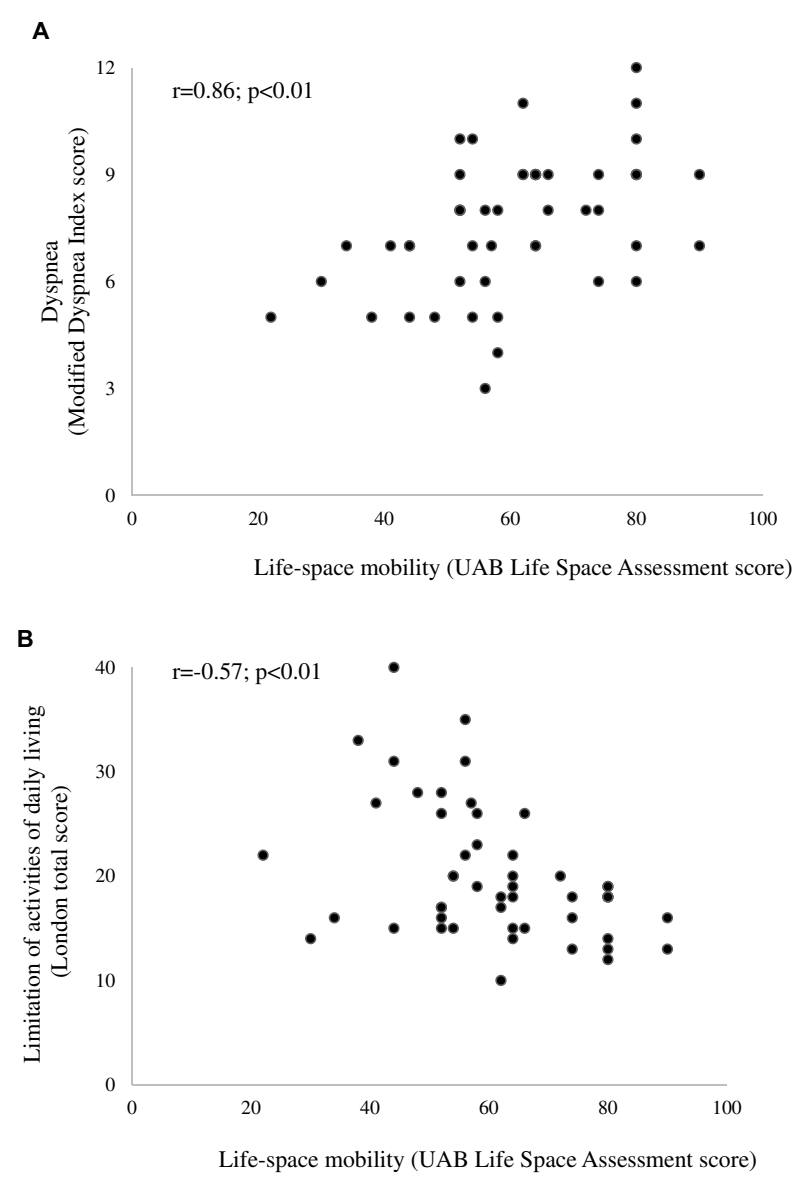

Figure 2 Correlations between Life-space mobility score of older adults with COPD and severity of dyspnea (A), and limitations of activities of daily living (B). Abbreviations: COPD, chronic obstructive pulmonary disease; UAB, University of Alabama at Birmingham.

COPD (limitation during the performance of activities of daily living) and the limited participation in social activities (life-space mobility) in this population.

The mobility of older people is associated with how well they maintain their functional independence as well as with their participation in social activities, ${ }^{22,23}$ which are of paramount importance for the well-being of this population. $^{24}$ Specifically, life-space mobility encompasses physiological and psychological abilities that an individual needs to move along different spaces/places. ${ }^{25}$ The assessment of life-space mobility quantifies the space,

Table 3 Variables Included in the Regression Model $(n=50)$

\begin{tabular}{|l|l|l|}
\hline Variables & $\mathbf{R}^{\mathbf{2}}$ & p-value \\
\hline London scale & 0.40 & $<0.001$ \\
London scale + Sex & 0.56 & 0.002 \\
\hline
\end{tabular}

Notes: $R^{2}$, coefficient of determination; $p$-value, statistical significance for the multiple linear regression.

Abbreviation: London scale, London Chest Activity of Daily Living. 
the frequency and the independence of older people traveling around the place where they live. ${ }^{15}$ Detecting this limitation supports a broader approach that aligns with the needs of these individuals to improve functional capacity. ${ }^{26}$ Older people with COPD frequently present with limitations pertaining to their social life and functional capacity, ${ }^{27}$ and our results confirm that their lifespace mobility is decreased, as previously detected. ${ }^{11}$ The systemic effects of COPD, such as peripheral muscle dysfunction and decreased exercise tolerance, may limit the performance of activities of daily living. ${ }^{28}$ And decreased physical activity levels are associated with life-space mobility in older people with COPD. ${ }^{11}$

The assessment of life-space mobility covers different activities performed by the individual inside and outside their home, including activities of daily living. ${ }^{15}$ Thus, limitations when traveling through life-spaces reflect limitations on the performance of activities of daily living. ${ }^{29}$ When life-space mobility is diminished, limitations in the performance of activities of daily living and the impairment in physical activity levels may form a vicious cycle, ${ }^{29}$ possibly resulting in loss of functional independence. ${ }^{30}$ In addition, restrictions on independent travel through life-spaces can predict exacerbations and are associated with decreased exercise tolerance, increased dyspnea, and poor quality of life in people with COPD. ${ }^{31}$

Our results demonstrated that the severity of dyspnea is associated with life-space mobility of older people with COPD. In a previous study that included individuals with COPD, a strong association between dyspnea and mobility in the living space was also observed $(r=-0.58$, $\mathrm{p}<0.001){ }^{31}$ although less strong than in our study ( $\mathrm{r}=$ $0.86, \mathrm{p}<0.01)$. Both results show that worsening COPD symptoms are probably associated with lower social participation of people with COPD. In addition, dyspnea and depression have been shown to be associated with lower levels of physical activity in this same population, ${ }^{32}$ as well as depression, has been shown to be associated with the worse disease control independently of the level of airways obstruction. ${ }^{33}$ Dyspnea is the main symptom of people with COPD, and it negatively affects their levels of physical activity. ${ }^{34}$ Thus, dyspnea may lead to physical inactivity and peripheral muscle deconditioning. ${ }^{35}$ And both peripheral muscle dysfunction and dyspnea impact life-space mobility of older people with COPD. ${ }^{11}$

Our results also demonstrated that the limitation during the performance of activities of daily living, assessed by the London Chest Activity of Daily Living scale, is associated with life-space mobility of older people with COPD. Previous studies reported similar findings in other populations of older people. ${ }^{16,36,37}$ Hence, interventions to increase independence in the performance of activities of daily living may result in improved quality of life of older people due to increased life-space mobility. ${ }^{38}$

The London Chest Activity of Daily Living scale used in our study is a valid and reliable tool to evaluate the dyspnea-related limitation during the performance of activities of daily living in people with COPD. ${ }^{2}$ This scale may also provide information on the effectiveness of therapeutic strategies included in pulmonary rehabilitation programs. ${ }^{39}$ In addition, our results demonstrated that the limitation during the performance of activities of daily living is an independent factor associated with life-space mobility in older people with COPD. Increased limitation during the performance of activities of daily living predicts decreased life-space mobility, and this is likely to predict poorer quality of life. ${ }^{38}$ Moreover, a previous study longitudinally identified that community-dwelling older people with reduced life-space mobility (LSA $<52.3$ points) were more likely to develop inability to perform activities of daily living after 2 years. Considering that the average LSA of our population was less than 50 points, we can conclude that older people with COPD are more fragile and more likely to become more dependent earlier. ${ }^{40}$ Reduction in life-space mobility is a predictor of poor cognition, ${ }^{41}$ decreased performance in activities of daily living, ${ }^{38}$ and higher nursing home admission in older people. ${ }^{42}$ Therefore, limitation during the performance of activities of daily living is an important clinical outcome for older people. ${ }^{40}$ Further, this outcome is a predictor of mortality in those with COPD. ${ }^{43}$

According to our results, sex is another factor in the regression model of life-space mobility of older people with COPD. Our hypothesis is that males with COPD have greater muscle strength and muscle mass, better exercise capacity, lower susceptibility to tobacco damage and pulmonary hyperresponsiveness compared to females. ${ }^{44}$ Further, males also present better functional capacity. ${ }^{45}$ A previous study on older people living in the community has shown that, after adjusting for age and other factors, males scored higher in the University of Alabama at Birmingham Study of Aging Life-Space Assessment questionnaire compared to females. ${ }^{15}$ Similar to the results of our study, in the regression model of that same previous study, $58 \%$ of the variability of scores obtained in the University of Alabama at Birmingham 
Study of Aging Life-Space Assessment questionnaire was mainly explained by the variables sex and physical abilities (Instrumental Activities of Daily Living and Short Physical Performance Battery). ${ }^{15}$

Maintaining the ability to move (wherever, whenever and however you prefer) is an important factor in the aging process. ${ }^{22}$ Impairments in mobility decrease social activity participation $^{22}$ and predict functional impairment in older people. ${ }^{46}$ And these are aggravated by COPD, a disease known for negatively impacting levels of physical activity. ${ }^{47}$ Further, low levels of physical activity in people with COPD are associated with higher hospital admission ${ }^{48}$ and poorer survival. ${ }^{49}$ Therefore, health professionals should be aware of the causes and develop interventions that may potentially increase mobility in older people with COPD who have impaired life-space mobility.

The University of Alabama at Birmingham Study of Aging Life-Space Assessment questionnaire has advantages over other instruments that only assess performance during activities of daily living or number of steps. ${ }^{50}$ This questionnaire takes into consideration the performance score and the need for personal assistance or equipment used for personal mobility. ${ }^{51}$ A minority of people assessed reached scores that were either very close to the maximum or very close to the minimum score. ${ }^{6,15}$ This finding has already been demonstrated in a previous study that was not able to detect ceiling and floor effects when applying this questionnaire in older people with COPD. ${ }^{52}$ In addition, the University of Alabama at Birmingham Study of Aging Life-Space Assessment questionnaire is inexpensive and can be completed in approximately 5 mins, either in person or via telephone. ${ }^{15}$

Thus, the assessment of life-space mobility should be included as a standard for older adults with COPD to investigate their real-life ability to participate in social activities, go to the pharmacy, to the market or to a park. For example, noticing real changes in mobility in their daily lives may more likely encourage the individual to remain physically active after the end of the pulmonary rehabilitation program than to know that he or she can walk more meters in a corridor. Therefore, the use of the University of Alabama at Birmingham Study of Aging Life-Space Assessment questionnaire should be a new strategy in programs such as pulmonary rehabilitation, both in research and clinical practice.

A limitation of our study is that participants' responses to the questions of University of Alabama at Birmingham Study of Aging Life-Space Assessment questionnaire relied on their ability to remember their mobility over the past month. However, most individuals were accompanied by a partner or close relative, who helped to validate their responses. Another limitation is that the mean age of our study participants is lower when compared to the mean age of participants in studies undertaken in developed countries. However, in developing countries such as Brazil, the World Health Organization considers older people those aged $\geq 60$ years old. ${ }^{53}$ Further, older people with COPD in developing countries should have similar health conditions when compared to older people in developed countries who have the same disease severity and are older. Finally, the number of participants in this study was small and they all came from the same hospital, probably with common social and economic characteristics. This was because this study was conducted with secondary data from a previously published study. ${ }^{11}$ However, for a correlation study, even being a convenience sample, 50 participants appear to be sufficient, since the test power for the primary outcome was calculated as $90 \%$. Further studies including participants from other locations and follow up may add relevant information to our initial findings.

\section{Conclusion}

In conclusion, the limitation during the performance of activities of daily living and dyspnea has a strong correlation with life-space mobility in older adults with COPD in this study. Furthermore, alongside sex, limitation during the performance of ADL is an independent factor associated with life-space mobility.

\section{Acknowledgments}

We thank the participants of this study. This project was funded by Fundação de Amparo à Pesquisa do Estado de São Paulo (FAPESP): grant numbers 2015/12614-9 and 2015/24982-2. The funding source had no role in the design and conduct of the study; collection, management, analysis, and interpretation of the data; or preparation, review, and approval of the manuscript. The study was conducted at the Pneumology service, Mandaqui's Hospital Group, São Paulo, SP, Brazil.

\section{Author Contributions}

IFFG, CTT, MSMPS, and ACL contributed to the concept and design of this study and undertook data analysis and interpretation. All authors contributed to data analysis, drafting or revising the article, gave final approval of the 
version to be published, and agree to be accountable for all aspects of the work.

\section{Disclosure}

Isabel Fialho Fontenele Garcia, Carina Tiemi Tiuganji, Maria do Socorro Morais Pereira Simões and Adriana Claudia Lunardi declare no conflicts of interest in this work.

\section{References}

1. Global Initiative for Chronic Obstructive Lung Disease (GOLD). Global strategy for the diagnosis, management and prevention of COPD [webpage on the Internet]. Available from: www.goldcopd. org. Accessed August 10, 2019.

2. Garrod R, Bestall JC, Paul EA, JÁ W, Jones PW. Development and validation of a standardized measure of activity of daily living in patients with severe COPD: the London Chest Activity of Daily Living scale (LCADL). Respir Med. 2000;94(6):589-596. doi:10.1053/rmed.2000.0786

3. Simon KM, Carpes MF, Corrêa KS, Santos K, Karloh M, Mayer AF. Relationship between daily living activities (ADL) limitation and the BODE index in patients with chronic obstructive pulmonary disease. Braz J Phys Ther. 2011;15(3):212-218. doi:10.1590/S1413-35552 011000300007

4. Jette AM. Toward a common language for function, disability, and health. Phys Ther. 2006;86(5):726-734.

5. Brown CJ, Roth DL, Allman RM, Sawyer P, Ritchie CS, Roseman JM. Trajectories of life-space mobility after hospitalization. Ann Intern Med. 2009;150(6):372-378. doi:10.7326/ 0003-4819-150-6-200903170-00005

6. Baker PS, Bodner EV, Allman RM. Measuring life-space mobility in community-dwelling older adults. J Am Geriatr Soc. 2003;51 (11):1610-1614. doi:10.1046/j.1532-5415.2003.51512.x

7. Makhija SK, Gilbert GH, Litaker MS, et al. Association between aspects of oral health-related quality of life and body mass index in community-dwelling older adults. J Am Geriatr Soc. 2007;55 (11):1808-1816. doi:10.1111/j.1532-5415.2007.01391.x

8. Wilkie R, Peat G, Thomas E, Croft P. The prevalence of person-perceived participation restriction in community-dwelling older adults. Qual Life Res. 2006;15(9):1471-1479. doi:10.1007/ s11136-006-0017-9

9. Locher JL, Ritchie CS, Roth DL, Baker PS, Bodner EV, Allman RM. Social isolation, support, and capital and nutritional risk in an older sample: ethnic and gender differences. Soc Sci Med. 2005;60 (4):747-761. doi:10.1016/j.socscimed.2004.06.023

10. Polku H, Mikkola TM, Portegijs E, et al. Life-space mobility and dimensions of depressive symptoms among community-dwelling older adults. Aging Ment Health. 2015;19(9):781-789.

11. Garcia IFF, Tiuganji CT, Simoes MDSMP, Santoro IL, Lunardi AC. Systemic effects of chronic obstructive pulmonary disease in young old adults' life-space mobility. Int J Chron Obstruct Pulmon Dis. 2017;27:2777-2785. doi:10.2147/COPD.S146041

12. National Institutes of Health (US). Clinical Guidelines on the Identification, Evaluation and Treatment of Overweight and Obesity in Adults. Bethesda: National Heart, Lung and Blood Institute; 1998.

13. Miller MR, Hankinson J, Brusasco V, et al. Standardisation of spirometry. Eur Respir J. 2005;26(2):319-338. doi:10.1183/09031936.05.00034805

14. Pereira CAC. Espirometria - diretrizes para Testes de Função Pulmonar. J Bras Pneumol. 2002;28(Suppl 3):S1-S82.

15. Peel C, Sawyer Baker P, Roth DL, Brown CJ, Bodner EV, Allman RM. Assessing mobility in older adults: the UAB Study of aging life-space assessment. Phys Ther. 2005;85(10):1008-1119.
16. Curcio CL, Alvarado BE, Gomez F, Guerra R, Guralnik J, Zunzunegui MV. Life-space assessment scale to assess mobility: validation in Latin American older women and men. Aging Clin Exp Res. 2013;25(5):553-560. doi:10.1007/s40520-013-0121-y

17. Simoes MDSMP, Garcia IFF, Costa LDC, Lunardi AC. Life-space assessment questionnaire: novel measurement properties for Brazilian community-dwelling older adults. Geriatr Gerontol Int. 2018;18 (5):783-789. doi:10.1111/ggi.13263

18. Allman RM, Sawyer P, Roseman JM. The UAB Study of Aging: background and insights into lifespace mobility among older Americans in rural and urban settings. Aging Health. 2006;2 (3):417-429. doi:10.2217/1745509X.2.3.417

19. Miura CTP, Gallani MCBJ, Domingues GBL, Rodrigues RCM, Stoller JK. Adaptação cultural e análise da confiabilidade do instrumento Modified Dyspnea Index para a cultura brasileira. Rev Latinoam Enferm. 2010;18(5):1020-1030. doi:10.1590/S010411692010000500025

20. Carpes MF, Mayer AF, Simon KM, Jardim JR, Garrod R. Versão brasileira da escala London Chest Activity of Daily Living para uso em pacientes com doença pulmonar obstrutiva crônica. J Bras Pneumol. 2008;34 (3):143-151. doi:10.1590/S1806-37132008000300004

21. Mokkink LB, Prinsen CA, Bouter LM, Vet HC, Terwee CB. The COnsensus-based Standards for the selection of health Measurement INstruments (COSMIN) and how to select an outcome measurement instrument. Braz J Phys Ther. 2016;20(2):105-113. doi:10.1590/bjptrbf.2014.0143

22. Satariano WA, Guralnik JM, Jackson RJ, Marottoli RA, Phelan EA, Prohaska TR. Mobility and aging: new directions for public health action. Am J Public Health. 2012;102(8):1508-1515. doi:10.2105/ AJPH.2011.300631

23. Rantakokko M, Mänty M, Rantanen T. Mobility decline in old age. Exerc Sport Sci Ver. 2013;41(1):19-25. doi:10.1097/JES.0b013e3182556fle

24. Depp CA, Jeste DV. Definitions and predictors of successful aging: a comprehensive review of larger quantitative studies. Am J Geriatr Psychiatry. 2006;14(1):6-20. doi:10.1097/01.JGP.0000192501.03069.bc

25. Barnes LL, Wilson RS, Bienias JL, et al. Correlates of life space in a volunteer cohort of older adults. Exp Aging Res. 2007;33(1):77-93. doi:10.1080/03610730601006420

26. Akishita M, Ishii S, Kojima T, et al. Priorities of health care outcomes for the elderly. $J$ Am Med Dir Assoc. 2013;14(7):479-484. doi:10.1016/j.jamda.2013.01.009

27. Yohannes AM, Roomi J, Waters K, Connolly MJ. Quality of life in elderly patients with COPD: measurement and predictive factors. Respir Med. 1998;92(10):1231-1236. doi:10.1016/S0954-6111(98) 90426-7

28. AGN A, Noguera A, Sauleda J, Sala E, Pons J, Busquets X. Systemic effects of chronic obstructive pulmonary disease. Eur Respir J. 2003;21(2):347-360. doi:10.1183/09031936.03.00405703

29. Portegijs E, Tsai LT, Rantanen T, Rantakokko M. Moving through greater lifespace areas and objectively measured physical activity of older people. PLoS One. 2015;10(8):e0135308. doi:10.1371/journal. pone. 0135308

30. Gill TM, Allore HG, Gahbauer EA, Han L. Establishing a hierarchy for the two components of restricted activity. J Gerontol a Biol Sci Med Sci. 2015;70(7):892-898. doi:10.1093/gerona/glu203

31. Iyer AS, Wells JM, Bhatt SP, et al. Life-space mobility and clinical outcomes in COPD. Int $J$ Chron Obstruct Pulmon Dis. 2018;13:2731-2738. doi:10.2147/COPD

32. Lee SH, Kim KU, Lee H, Kim YS, Lee MK, Park HK. Factors associated with low-level physical activity in elderly patients with chronic obstructive pulmonary disease. Korean J Intern Med. 2018;33(1):130-137. doi:10.3904/kjim.2016.090

33. Borges-Santos E, Wada JT, da Silva CM, et al. Anxiety and depression are related to dyspnea and clinical control but not with thoracoabdominal mechanics in patients with COPD. Respir Physiol Neurobiol. 2015;210:1-6. doi:10.1016/j.resp.2015.01.011 
34. Barriga S, Rodrigues F, Bárbara C. Factors that influence physical activity in the daily life of male patients with chronic obstructive pulmonary disease. Rev Port Pneumol. 2014;20(3):131-137. doi:10.1016/j.rppneu.2013.09.004

35. O'Donnell DE. Hyperinflation, dyspnea, and exercise intolerance in chronic obstructive pulmonary disease. Proc Am Thorac Soc. 2006;3 (2):180-184. doi:10.1513/pats.200508-093DO

36. Mackey DC, Cauley JA, Barrett-Connor E, et al. Life-Space Mobility and Mortality in older men: a prospective cohort study. J Am Geriatr Soc. 2014;62(7):1288-1296.

37. Al Snih S, Peek KM, Sawyer P, Markides KS, Allman RM, Ottenbacher KJ. Life-space mobility in Mexican Americans aged 75 and older. J Am Geriatr Soc. 2012;60(3):532-537. doi:10.1111/ j.1532-5415.2011.03822.x

38. Bentley JP, Brown CJ, Mcgwin G Jr, Sawyer P, Allman RM, Roth DL. Functional status, life-space mobility, and quality of life: a longitudinal mediation analysis. Qual Life Res. 2013;22 (7):1621-1632. doi:10.1007/s11136-012-0315-3

39. Garrod R, Paul EA, Wedzicha JA. An evaluation of the reliability and sensitivity of the London Chest Activity of Daily Living Scale(LCADL). Respir Med. 2002;96(9):725-730. doi:10.1053/rmed.2002.1338

40. Portegijs E, Rantakokko M, Viljanen A, Sipilä S, Rantanen T. Identification of older people at risk of ADL disability using the life-space assessment: a longitudinal cohort study. J Am Med Dir Assoc. 2016;17(5):410-414. doi:10.1016/j.jamda.2015.12.010

41. Crowe M, Andel R, Wadley VG, Okonkwo OC, Sawyer P, Allman RM. Life-space and cognitive decline in a community-based sample of African American and Caucasian older adults. J Gerontol a Biol Sci Med Sci. 2008;63(11):1241-1245. doi:10.1093/gerona/63.11.1241

42. Sheppard KD, Sawyer P, Ritchie CS, Allman RM, Brown CJ. Life-space mobility predicts nursing home admission over 6 years. J Aging Health. 2013;25(6):907-920. doi:10.1177/0898264313497507

43. Millán-Calenti JC, Tubío J, Pita-Fernández S, et al. Prevalence of functional disability in activities of daily living (ADLs), instrumental activities of daily living (IADLs) and associated factors, as predictors of morbidity and mortality. Arch Gerontol Geriatr. 2010;50 (3):306-310. doi:10.1016/j.archger.2009.04.017
44. Torres JP, Casanova C, Hernández C, Abreu J, Aguirre-Jaime A, Celli BR. Gender and COPD in patients attending a pulmonary clinic. Chest. 2005;128(4):2012-2016. doi:10.1378/chest.128.4.2012

45. Leveille SG, Penninx BW, Melzer D, Izmirlian G, Guralnik JM. Sex differences in the prevalence of mobility disability in old age: the dynamics of incidence, recovery, and mortality. J Gerontol Soc Sci. 2000;55(1):S41-S50.

46. Hirvensalo M, Rantanen T, Heikkinen E. Mobility difficulties and physical activity as predictors of mortality and loss of independence in the community-living older population. J Am Geriatr Soc. 2000;48 (5):493-498. doi:10.1111/jgs.2000.48.issue-5

47. Vorrink SN, Kort HS, Troosters T, Lammers JW. Level of daily physical activity in individuals with COPD compared with healthy controls. Respir Res. 2011;12:33. doi:10.1186/1465-9921-12-33

48. Garcia-Aymerich J, Farrero E, Felez MA, Izquierdo J, Marrades RM, Anto JM. Risk factors of readmission to hospital for a COPD exacerbation: a prospective study. Thorax. 2003;58(2):100-105. doi:10.1136/thorax. 58.2 .100

49. Yohannes AM, Baldwin RC, Connolly M. Mortality predictors in disabling chronic obstructive pulmonary disease in old age. Age Ageing. 2002;31(2):137-140. doi:10.1093/ageing/31.2.137

50. Kennedy RE, Sawyer P, Williams CP, et al. Life-space mobility change predicts 6-month mortality. J Am Geriatr Soc. 2017;65 (4):833-838. doi:10.1111/jgs.14738

51. Baker PS, Bodner EV, Carpesra CJ, Kennedy RE, Allman RM. Lifespace assessment composite score rationale. Clin Rehabil. 2016;30 (1):95-97. doi:10.1177/0269215515614295

52. Garcia IFF, Tiuganji CT, MDSMP S, Lunardi AC. A study of measurement properties of the life space assessment questionnaire in older adults with chronic obstructive pulmonary disease. Clin Rehabil. 2018;32(10):1374-1382. doi:10.1177/0269215518780488

53. Nations U. Current Status of the Social Situation, Well-Being, Participation in Development and Rights of Older Persons Worldwide. New York: United Nations; 2011:99.

\section{Publish your work in this journal}

The International Journal of COPD is an international, peer-reviewed journal of therapeutics and pharmacology focusing on concise rapid reporting of clinical studies and reviews in COPD. Special focus is given to the pathophysiological processes underlying the disease, intervention programs, patient focused education, and self management protocols. This journal is indexed on PubMed Central, MedLine and CAS. The manuscript management system is completely online and includes a very quick and fair peer-review system, which is all easy to use. Visit http://www.dovepress.com/testimonials.php to read real quotes from published authors. 